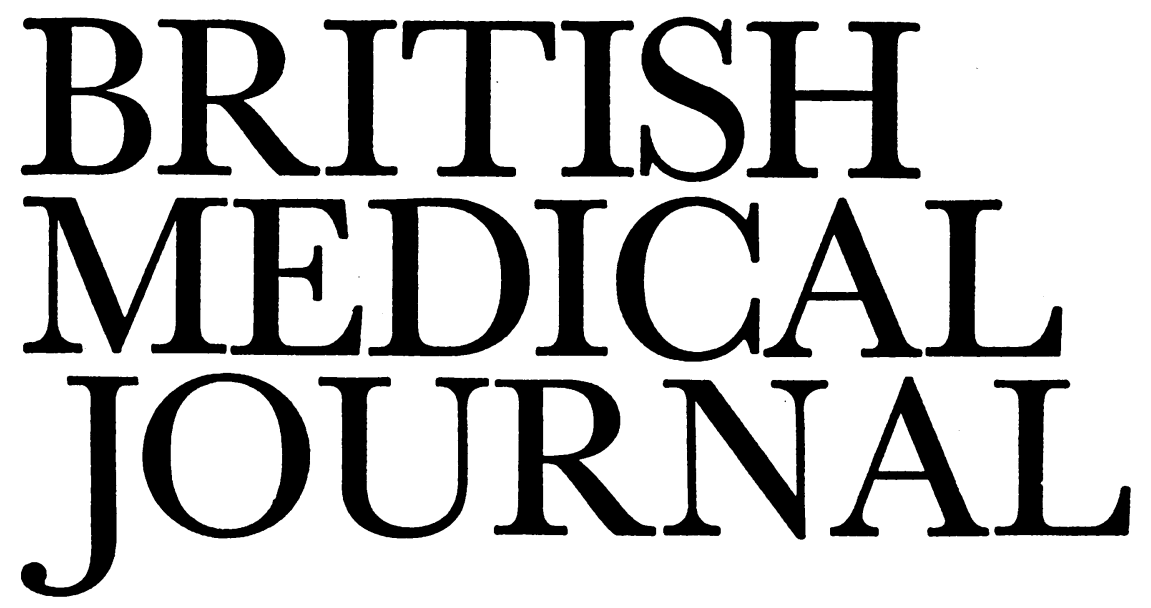

LONDON SATURDAY 20 JANUARY 1973

\title{
Cranial Arteralgias
}

The source of headache in granulomatous inflammation of the temporal arteries can be easily identified. 1 The blood vessels are tender on pressure, and pain can usually be relieved by procaine block or by ligature of the artery. Tenderness of an extracranial artery and the relief of pain derived from block of the artery provide, therefore, the criteria diagnostic of the group of headaches of extracranial arterial origin.

When present, the pulsating and throbbing character of the headache provides yet another pointer to the arterial origin of the headache. The pain of migraine belongs to this group, since there is usually some tenderness of a segment of the temporal artery, and the headache is of a throbbing character. The latter phenomenon is "what the common people in this country call 'opening and shutting'," according to Caleb Hillier Parry ${ }^{2}$ (1755-1822), "vir probus, medicus sagax," as he was described by his contemporaries. Under pretence of feeling the pulse of the neck he took the opportunity to press strongly with his thumb on the carotid artery a little below the larynx. "I do not remember having experienced a philosophical pleasure in any degree comparable to that which this experiment afforded to me. No sooner was the pressure made than the austerity of the countenance disappeared. At the same time the headache and undue sensibility with regard to light and sound were altogether wanting ... . Since the period of this discovery I have made the experiment with success. It nearly totally removes the hemicrania of the side on which the compression is made."2

Lowering of the pain threshold of an artery results in pain even when the pulsations are within the normal range. Obliteration of the pulsations, or the application of local anaesthesia to the relevant segment of the artery will relieve this pain. Yet careful scrutiny of the affected temporal artery excised at the height of a migraine attack fails to disclose any structural change. ${ }^{3}$ Since even severe dilatation of an extracranial artery under physiological conditions fails to give rise to pain, the hypothesis has been put forward that the release, in relation to an artery, of pain-producing substances, of a type which had been found in the plasma, may be responsible for lowering the pain threshold of the affected segment of the artery. ${ }^{45}$ This inference has been confirmed by the discovery of a humoral agent in the tissue fluid withdrawn from the subcutaneous region in the territory of tenderness from patients who were in the throes of migrainous headache. The active agent was found to be a substance similar to "plasma kinin." It was labelled "neurokinin" and was found to be similar to that released into the tissue fluid of the skin of a man after dorsal root stimulation. 6 It may be mentioned here that injection of bradykinin near a vein on the back of the hand produces pain, especially when the vein has been pretreated with serotonin. ${ }^{7}$

Benjamin Hutchinson, in the nineteenth century, described a "hemicrania" which, after recurring for several hours daily for long periods, "departs suddenly."8 This syndrome was rediscovered in recent years and is now known as cluster headache.910 Its features are well recognized and can be summarized as follows: for each individual patient the pain is of stereotyped character, position, and duration, usually 15-30 minutes; it is often of throbbing nature, and it is of high intensity. Attacks usually begin in the late teens or early 20 s and recur once or at most several times in 24 hours. Occasionally they are exclusively nocturnal. The overwhelming proportion of the patients are male, and they are almost always free from headaches of migrainous type. Periods of remission vary from months to years. Exceptionally, the spontaneous remissions, which constitute one of the most characteristic features, may be absent, and then "suicide headache" can be accepted as a suitable name for this syndrome, which is now recognized as also originating in one of the branches of the carotid tree. ${ }^{11}$

Further evidence of a periarterial morbid process in migraine is provided by the occasional associated oculomotor nerve palsy and, in the case of cluster headache, by an equally transient cervical sympathetic paralysis. ${ }^{12} 13$ Though the pain mechanisms in migraine and cluster headaches may be broadly similar, the two conditions must at present be regarded as distinct. Thus, intramuscular injection of $2.5 \mathrm{mg}$ of reserpine induces a headache in a migrainous subject, but cluster headaches are provoked by an injection of $1 \mathrm{mg}$ of histamine in a suitable subject. ${ }^{14} 15$

Migraine, even when reserpine induced, is associated with a fall of blood serotonin, but there is a rise of blood histamine during a "cluster" headache. ${ }^{16} 17$ Tyramine, an amine present in some foods, which is capable of releasing a number of biogenic monoamines in the body, can, when ingested in an adequate amount, cause a headache in some migrainous subjects. ${ }^{18}$ A recent study, which did not include normal controls, showed that in nearly half the migrainous persons tested tyramine produced electroencephalographic abnormalities. ${ }^{19}$ 
In Sir Thomas Lewis's laboratory in the early 1930s intravenous injection of histamine was used to measure the circulation time. Sir George Pickering noticed that the injections were followed in most persons by a severe bilateral headache of throbbing character and of a few minutes' duration. ${ }^{20}$ Intravenous injection of histamine is followed by vasodilatation, associated with a sharp drop in the blood pressure. After 30 seconds the blood pressure begins to rise and the headache becomes maximal, when the blood pressure returns to the normal level. During this phase pulsations of the cerebrospinal fluid pressure are also maximal. ${ }^{21}$

It has therefore been concluded that the large pulsations reflect corresponding exaggerated pulsations of the intracranial arteries, which are slower to recover their preinjection tone. Histamine headache can be relieved either by reducing blood pressure by further injections of histamine, or by raising the cerebrospinal fluid pressure by an intrathecal injection of warm normal saline solution. Parry's manoeuvre ${ }^{2}$ also promptly relieves the headache on the side on which it is applied. All these phenomena help to establish that relaxation of the intracranial arteries, unlike that of the extracranial arteries, gives rise to pain.

The mechanism of many forms of generalized throbbing headaches-among them the pyrexial or "typhoid" headaches-is similar to the histamine headache. Kinin-forming enzymes were found in the cerebrospinal fluid as frequently in the migrainous as in the control subjects. ${ }^{22}$ The relaxation of tone, and consequent excessive pulsation of intracranial arteries, may also account for pain in some cases of migraine. The headache in these cases is generalized and is aggravated by jolting. By means of a technique involving intracarotid injection of radioactive xenon it has been shown that at the height of this type of migrainous headache the cerebral blood flow is increased by $50 \%$, presumably because of the regional dilatation of the intracranial arteries. ${ }^{23}$ Histamine headache cannot be prevented by previous treatment with ergotamine, which is equally ineffective in the treatment of all other forms of intracranial arteralgias. Ergotamine given by mouth, because of vagaries of its fate after ingestion, is probably ineffective in all but a few cases of migraine, as was shown in a recent controlled clinical trial. 24

Ergot for the treatment of "periodic neuralgias" was first introduced by W. H. Thomson of New York, late in the nineteenth century, and though it remains the most effective drug in the treatment of extracranial arteralgia of migraine when given by some other than the oral route its pharmacological action remains conjectural. ${ }^{25}$ Since the use of placebos in migraine is followed by improvement in some $30 \%$ of cases, the evaluation of a large number of new antimigraine drugs presents considerable difficulty. ${ }^{26}$

Intracranial aneurysms must be mentioned among lesions causing intracranial arteralgias. A persistent localized throbbing headache, relieved temporarily by ipsilateral carotid compression, must arouse the suspicion of this possibility. Many new observations have been reported at two symposia on migraine held recently. ${ }^{27} 28$ Much of this is still controversial and some may prove ephemeral. Cranial arteralgias represent but one facet of the migraine complex. ${ }^{29}$

\footnotetext{
1 Horton, B. T., Magath, T. B., and Brown, G. E., Archives of Internal Medicine, 1934, 53, 400 .

2 Parry, C. H., Memoirs of the Medical Society of London, 1792, 3, 77.

3 Adams, C. W. M., Orton, C. C., and Zilkha, K. J., Fournal of Neurology, Neurosurgery, and Psychiatry, 1968, 31, 50.

- Behrman, S., Annals of the Royal College of Surgeons of England, 1957,

21, 382. Physiology, 1957, 135, 350.
}

- Chapman, L. F., Ramos, A. O., Goodell, H., Silverman, G., and Wolff, H. G., Archives of Neurology, 1960, 3, 223.

Sicuteri, F., in Research and Clinical Studies in Headache, ed. A. P. Friedman, 1, 6. Basle, S. Karger, 1967.

${ }^{8}$ Hutchinson, B., Cases of Neuralgia Spasmodica, 2nd edn. London,

- Harris, W., Neuritis and Neuralgia, p. 145. London, Oxford University Press, 1926.

10 Horton, B. T., Maclean, A. R., and Craig, W. M., Proceedings of the Staff Meetings of the Mayo Clinic, 1939, 14, 257.

11 Roberts, S. E., Laryngoscope, 1954, 64, 35.

12 Alpers, B. J., and Yaskin, H. E., Archives of Ophthalmology, 1951, 45, 555. Nieman, E. A., and Hurwitz, L. J., fournal of Neurology, Neurosurgery and Psychiatry, 1961, 24, 369.

14 Kimball, R. W., Friedman, A. P., and Vallejo, E., Neurology, 1960, 10, 107.

15 Horton, B. T., Fournal of the American Medical Association, 1941, 116, 377 ${ }^{16}$ Anthony, M., Hinterberger, H., and Lance, J. W., Archives of Neurology,. $1967,16,544$.

17 Anthony, M., and Lance, J. W., Archives of Neurology, 1971, 25, 22.

18 Hanington, E., British Medical fournal, 1967, 2, 550.

19 Moffett, A., Swash, M., and Scott, D. F., fournal of Neurology, Neuro-

20 Pickering, and Psychiatry, 1972, 35, 496.
s., British Medical fournal, 1939, $1,907$.

21 Clark, D., Hough, H., and Wolf, H. G., Associaticn for Research in Nervous and Mental Disease Proceedings, 1935, 15, 417.

22 Barrie, M., and Jowett, A., Brain, 1967, 90, 785.

3 Skinhoj, E., quoted by Lance, J. W., Medical fournal of Australia, Special Supplement, $1972,2,3$.

24 Waters, W. E., British Medical fournal, 1970, 2, 325.

25 Thomson, W. H., Fournal of Nervous and Mental Diseases, 1894, 19, 124. Lance, J. W., Medical fournal of Australia, Special Supplement, 1972 2,29 .

7 Symposium on Migraine and Hypertension, Medical fournal of Australia, Special Supplement, 1972, $2,3$.

8 Cumings, J. N., (editor), Background to Migraine, vol. 5. Heinemann, London (in press).

29 Blau, J. N., Wilkinson, M., and Carroll, J. D., British Medical fournal, $1971,2,751$.

\section{Food for Thinking}

The last decade has seen a resurgence of interest in the idea that malnutrition in early life may permanently impair an individual's higher mental function. The importance of the question is difficult to exaggerate, since we are dealing here with the possible effects on man's intellect of one of his greatest self-inflicted scourges-the malnutrition of most of the world's children. Now as a result of treatment some children have survived who a decade or so ago would have died miserably of their starvation. Such survivors are likely to increase in number owing to a growing understanding of nutritional disease and a consequent greater skill in its clinical management. As in the field of perinatal paediatrics, there must now be a concern for the quality as well as for the quantity of the survivors.

The complexities of the deceptively simple basic question are now appreciated. ${ }^{1}$ H. G. Birch, J. Tizard, and their associates have recently published one of the most compelling demonstrations that malnutrition itself does have a separate role in the impairment of intellectual achievement apart from the other environmental handicaps which inevitably accompany it in human society. These investigators, M. E. Hertzig and colleagues, ${ }^{2}$ have studied 74 Jamaican children treated in hospital for severe clinical malnutrition before their second birthday in the Tropical Metabolism Research Unit of the Medical Research Council. The children received excellent and well-documented hospital care, a long convalescence, and two years of public health nursing care after discharge. And it has been possible to follow their progress in their community from 5 to 12 years of age. They have now been compared with two control groups who had no history of overt nutritional disease-38 siblings closest to them in age, and 71 unrelated matched classmates or neighbours. Reports on their social and school functioning are promised for the future.

The findings are that the control sibs matched up to the 